\title{
Quality changes of dried persimmon based on storage conditions
}

\author{
Ji-Young Choi ${ }^{1}$, Jeong-Seok Jo ${ }^{1}$, Hyeon-Jeong Lee ${ }^{1}$, Jin-Ho Woo ${ }^{1}$, Su-Hyeon Heo ${ }^{1}$, \\ $\mathrm{Su}^{-I n} \mathrm{Bae}^{1}$, Kwang-Deog Moon ${ }^{1,2 *}$ \\ School of Food Science and Technology, Kyungpook National University, Daegu 41566, Korea \\ ${ }^{2}$ Food and Bio-industry Research Institute, Kyungpook National University Daegu 41566, Korea
}

\section{농가별 저장조건에 따른 건시의 품질 특성 변화}

\author{
최지영 ${ }^{1} \cdot$ 조정석 ${ }^{1} \cdot$ 이현정 $^{1} \cdot$ 우진호 $^{1} \cdot$ 허수현 $^{1} \cdot$ 배수인 $^{1} \cdot$ 문광덕 $^{1,2 *}$ \\ '경북대학교 식품공학부 식품생물공학전공, ${ }^{2}$ 경북대학교 식품생물산업연구소
}

\begin{abstract}
The purpose of this study is to present the results as basic data for establishing proper storage conditions and distribution conditions of actual farms at point of increasing concern about hygiene and palatabiltiy of consumers to food. In this study, three farmhouses of dried persimmons prepared using different storage conditions were selected in Sangju (Korea). The dried persimmons were stored for 90 days. Changes in temperature and humidity were measured with a temperature and humidity recorder under each storage condition, and physicochemical analysis and sensory evaluation were performed. The average temperatures of farmhouse $\mathrm{A}, \mathrm{B}$ and $\mathrm{C}$ were approximately $-22--23{ }^{\circ} \mathrm{C},-19--18{ }^{\circ} \mathrm{C}$ and $-25^{\circ} \mathrm{C}$ respectively. The humidities of $\mathrm{A}, \mathrm{B}$ and $\mathrm{C}$ were $62-63 \%, 59-60 \%$, and $66-67 \%$, respectively, and the moisture contents of all farmhouses increased during the storage period, with farmhouse $\mathrm{B}$ showing the most rapid increase. Free sugars increased, except for those from farmhouse C. Persimmons from farmhouse $B$ showed the greatest changes in chewiness and hardness. The values of $a^{*}$ and $b^{*}$ were significantly decreased in persimmons from farmhouse $B$, and the color difference value of farmhouse $B$ was dramatically increased. Sensory evaluation showed that the color preference tended to decrease compared with the initial value. Only farmhouse B showed decreased overall acceptability. Moreover, farmhouse B had the highest storage temperature and lowest humidity. Therefore, our results showed that storage at a low temperature and high humidity was important for manufacturing high-quality dried persimmons.
\end{abstract}

Key words : farmhouse, storage condition, dried persimmon, quality, comparison

\section{서 론}

감(Diospryros kaki Thunb.)은 우리나라를 비롯하여 중국, 일본 등 온대아시아 지역이 원산지로 한국에서는 일찍부터 재배한 과일로서 향약구급방(師藥救急方)에 경상도 고령에 서 감을 재배하였다는 기록이 있다(1). 감의 주성분은 당질 로써 포도당과 과당의 함유량이 많으며, 이는 단감과 떫은

*Corresponding author. E-mail : kdmoon@knu.ac.kr Phone : 82-53-950-5773, Fax : 82-53-950-6772

Received 18 January 2018; Revised 21 February 2018; Accepted 21 February 2018.

Copyright (c) The Korean Society of Food Preservation. All rights reserved.
감에 따라 약간의 차이가 있다(2). 또한 비타민 $\mathrm{A}, \mathrm{B}$ 가 풍부 하고 비타민 C는 $100 \mathrm{~g}$ 중에 30-50 mg이 함유되어 있다(1). 감은 기침 등에 효과가 있으며, 다른 과실과 달리 신맛이 없고 탄닌의 수렴작용으로 설사를 멎게 하거나 이뇨, 지혈, 숙취제거, 기침 등의 약리작용을 나타내어 예로부터 많이 사용되어 온 기능성이 우수한 전통 과일 중의 하나이다(3). 감 가공 식품 중 곶감은 건시라고도 불리며, 우리나라에서 는 주로 경북 상주, 청도 경남 함안, 충북 영동, 전북 완주가 대표적인 산지이며, 떫은 감의 $50 \%$ 이상이 곶감으로 가공 되고 있다(4). 곶감은 가을에 일시적으로 다량 출하되는 감 과실로 이용기간을 연장하는 가장 중요한 수단일 뿐 아니라 풍부한 감미와 특유의 물질적 특성을 지니고 있는 우수한 건조식품이다(5,6). 곶감은 주로 농가에서 생산과 
저장을 모두 거쳐 판매되기 때문에 고품질의 상태로 연중유 통하기 위해서는 장기저장 기술의 개발이 필수적이며, 저 장온도에 따른 품질 차이를 구명하는 것이 매우 중요하다. 상품화된 곶감은 대개 $35-50 \%$ 내외의 수분 함유 상태로 유통되고 있으나(7) 조직이 질기고 딱딱하며 표면의 하얀 분의 과다발생 등으로 인하여 기호도 및 상품성이 저하된 다. 또한 감을 건조하는 과정, 건조 후 장기간 저장 유통하는 과정 중에 곰팡이, 유충의 발생으로 인하여 품질이 변질되 어 위생상태가 급격히 떨어지게 된다. 곶감의 장기 유통 과정에 발생되는 품질저하를 방지하기 위하여 자몽종자 추출물 처리와 포장방법에 따른 반건시 곶감의 품질변화 (8), 계피 추출물 처리와 포장방법에 따른 곶감의 품질변화 (9), 전처리와 포장재에 따른 곶감 품질변화(10) 등의 연구 들이 보고되어 있다. 기존 연구에서 곶감을 장기간 저장하 기 위해서는 수분을 36-39\% 정도 유지하고 상대습도는 75-80\%로 유지하여 저온 유통하는 것이 바람직하며 무포 장 곶감은 상온에서 상대습도 $75 \%$ 를 유지하면 2-3개월, 저온 저장 시 상대습도 $75 \%$ 에서는 3 개월 이상 품질 유지가 가능하다고 보고하였다(11).

본 연구의 시료로 사용된 둥시품종의 재배면적은 전체 떫은감 재배면적 16,564 ha 중에서 두 번째로 넓은 5,500 $\mathrm{ha}$ 를 차지하며(12), 시료를 구입한 상주 지역은 떫은 감 생산량이 2016년에 조사 시 39,075톤으로 전국 생산량의 약 $21 \%$ 로 떫은 감의 주산지로 보고 있다(13). 전체 재배품 종 중 $32.2 \%$ 를 차지하며, 432 억원을 생산하는 둥시 품종 저장 조건에 대해서 관찰하였다(14,15). 본 연구는 소비자 들의 식품에 대한 위생성, 기호성에 대한 관심이 증대되고 있는 시점에서, 실제 농가에서의 적합한 건시의 저장 및 유통 조건을 설정하기 위한 기초자료로써 결과를 제시하고 자 하였다.

\section{재료 및 방법}

\section{실험재료 및 저장방법}

본 연구에 사용된 시료는 2016년 생산된 상주 둥시 품종 (D kaki Thunb.)으로 서로 다른 조건으로 저장중인 경북 상주 곶감 농가 3 곳을 선정하여 각각의 천일 건조된 건시를 구입 후 저장하였다. 건시의 포장은 기존의 농가에서 사용 하고 있는 포장방법을 그대로 이용하였다. 시료는 상주시 거동동, 외남면, 내서면에서 각각 1 곳씩 선정한 농가에서 생산된 감을 사용했으며 이를 각각 $\mathrm{OP}($ Oenam-myeon persimmons), GP(Geodong-dong persimmons), NP(Naeseomyeon persimmons)로 지칭하였다. 저장된 건시는 30 일 간 격으로 각 농가의 시료를 취하여 품질 변화를 조사하고 분석하였다.
저장 중 내부 온습도 변화

저장이 시작된 후부터 온습도 기록계(Temp \& RH data Logger, TM-305U, TENMARS, Taipei, Taiwan)를 10분 간격 으로 저장고 내부의 온습도 변화를 측정할 수 있도록 설정 한 뒤, 각 농가의 저장고에 안정적으로 설치하여 관찰하였 다. 또한 실험 기간 동안 실제 저장고의 내부 저장 조건과 온습도의 미세한 변화가 건시의 품질에 영향을 미치는 가에 대하여 연구하였다.

\section{색 도}

색도의 측정은 임의의 시료 3 개를 선택하여 외부와 내부 로 나눈 후, 5 회 반복 측정하였다. 백색판 $\left(\mathrm{L}^{*}=97.79\right.$, $\left.\mathrm{a}^{*}=-0.38, \mathrm{~b}^{*}=2.05\right)$ 으로 보정된 Colorimeter(CR-400, Minolta, Tokyo, Japan)을 이용하여, $\mathrm{L}^{*}$ (lightness), $\mathrm{a}^{*}$ (redness), $\mathrm{b}^{*}$ (yellowness) 값을 측정하여 평균값을 이용하였으며, 전반 적인 색차는 $\Delta \mathrm{E}\left(\Delta^{2}+\Delta b^{*_{2}}+\Delta^{*_{2}}\right)$ 값으로 나타내었다.

\section{수분 함량}

농가별 건시의 수분함량 변화는 $\mathrm{AOAC}(16)$ 방법에 준하 여 건시는 당분을 많이 함유한 식품이므로 $103^{\circ} \mathrm{C}$ 에서 상압 가열법을 이용하여 측정하였다. 측정 후 결과를 다음 식에 따라 백분율로 나타내었다.

$$
\text { 수분 }(\%)=\frac{\text { 칭량접시의 검체의 무게 }(\mathrm{g}) \text { 건조 후 항량이 되었을 때의 무게 }(\mathrm{g})}{\text { 칭량접시와 검체의 무게 }(\mathrm{g}) \text { 칭량접시의 무게 }(\mathrm{g})} \times 100
$$

\section{유리당 함량 측정}

유리당 함량 분석은 건시 $40 \mathrm{~g}$ 에 증류수 $360 \mathrm{~mL}$ 을 가하여 핸드 블랜더(SMX-355CHC, Shinil, Seoul, Korea)로 마쇄 후, $50 \mathrm{~mL}$ 을 취하여 증류수로 채운 $50^{\circ} \mathrm{C}$ 로 설정한 초음파 발생기(40 kHz, Daihan Scientific Co., Ltd., Seoul, Korea)를 이용하여 1 시간동안 초음파 추출하였다. 추출물을 5 분간 원심분리하고 상등액을 $0.45 \mu \mathrm{m}$ membrane filter로 여과 후 high performance liquid chromatography(HPLC)로 분석 을 실시하였다. 사용된 HPLC(Model Prominence, Shimadzu Co., Tokyo, Japan)는 Sugar-Pak I column $(\varnothing 6.5 \times 300 \mathrm{~mm}$; Waters Co.)을 사용하여 분석하였고 표준품은 glucose (Sigma chemical Co., St. Louis, MO, USA), fructose(Sigma chemical Co.), sucrose(Sigma chemical Co.), mannitol(Sigma chemical Co.), sorbitol(Sigma chemical Co.), raffinose(Sigma chemical Co.), galactose(Sigma chemical Co.)를 일정량 혼합 하여 표준용액으로 사용하였다. 표준품과 시료의 당성분은 머무른 시간(RT)을 비교하여 확인하였으며, 각 표준품의 검량곡선을 세워 peak의 면적으로 각각의 당 함량을 산출하 였다.

조직감

농가별로 저장된 건시의 물성은 Rheometer(Compac-100 
I, SunScientific Co., Tokyo, Japan)을 사용하여 측정하였 다. Prove는 No.1( $\Phi 20 \mathrm{~mm}$ )를 선택하여 부착하였으며, table speed는 $200 \mathrm{~mm} / \mathrm{min}$, prove의 진입거리는 시료의 $40 \%$ 로 조건 설정을 하였다. 임의로 시료를 선택하여 10 회 반복 측정하여, 그 값들의 평균값을 분석에 이용하였고 hardness, springiness, chewiness, cohesiveness를 측정항목으로 하였다.

\section{관능검사}

건시의 최적 저장조건을 설정하기 위해 전문적으로 숙련 된 경북대학교 식품공학부 대학원생 15 명을 대상으로 색 (color), 조직감(texture), 향(flavor), 단맛(sweetness), 외관 (appearance), 전반적 기호도(overall acceptance)에 대한 관 능검사를 실시하였다. 각 시료에 대한 평점은 7점 척도법(7 점, 매우좋음; 5-6점, 좋음; 4점, 보통; 2-3점, 나쁨; 1점, 매우 나쁨)으로 나타내었다. 또한 4점 이하는 상품적 가치가 없 는 것으로 평가 하였다. 또한 본 연구의 관능평가는 경북대 학교 생명윤리심의위원회의 규정에 따라 심의하여 승인번 호(2018-0005)를 받아 진행하였다.

\section{통계분석}

본 실험의 유의성 검정을 위해 SPSS(version 14.0, SPSS Inc., Chicago, IL, USA) 프로그램을 사용하여 $\mathrm{p}<0.05$ 수준 에서 Duncan's multiple range test 방법을 사용하여 통계처 리 하였으며, 실험결과는 Average $\pm \mathrm{SD}$ 로 나타내었다. 모든 실험의 측정값은 신뢰성을 확보하기 위하여 3회 이상 반복 하였다.

\section{결과 및 고찰}

\section{농가별 온습도 변화}

곶감은 원료 농산물이 아니라 원료인 떫은 감을 이용하 여 가공한 1 차 가공품이라는 상품적 특성을 지니고 있어 곶감 생산 농가는 단순히 농산물을 생산하는 것이 아니라 농산물 가공품을 생산하는 제조업이라고도 볼 수 있다. 생 산도 중요하지만 일관성 있는 저장조건도 중요하므로 현재 곶감농가에 실제로 적용되고 온습도 변화를 살펴보았다. 농가별 온습도 변화를 측정한 결과는 Fig. 1에 나타내었다. 0점을 기준으로 위쪽은 저장고의 습도변화를 나타내며, 아 래쪽은 온도변화를 나타낸다. $\mathrm{OP}$ 의 저장조건 변화를 관찰 해 보았을 때, 저장온도는 변화 폭은 나머지 농가에 비해 일정했고 최대값은 $-5.70^{\circ} \mathrm{C}$ 였으며, 최소값은 $-25.00^{\circ} \mathrm{C}$, 평균 온도는 $-22.89^{\circ} \mathrm{C}$ 였다. 또한 습도는 최대 $93.30 \%$, 최소 $50.00 \%$ 로 변화했고, 평균 습도는 $62.11 \%$ 였다. GP는 다른 농가에 비해 높은 온도인 $-16.52^{\circ} \mathrm{C}$ 를 평균적으로 나타났으 며, 최대 $10^{\circ} \mathrm{C}$, 최소 $-21.60^{\circ} \mathrm{C}$ 였다. 저장 기간 동안 저장온도 가 약간 증가하는 모습을 보였다. 습도는 변화가 심하고
변화 폭이 일정하지 않았으며, 최대 $99.50 \%$, 최소 $35.70 \%$ 까 지 변화하였다. $\mathrm{GP}$ 의 습도는 평균 $60.91 \%$ 였다. NP는 저장 기간 중 온습도가 급변하는 모습이 다소 나타났고 평균온도 는 $\mathrm{OP}$ 와 유사한 $-22.07^{\circ} \mathrm{C}$ 였으며, 변화폭은 $-28.70^{\circ} \mathrm{C}$ 에서 $-5.70^{\circ} \mathrm{C}$ 였다. 평균습도는 가장 높은 $69.42 \%$ 였다. 온도 변화 폭은 $\mathrm{OP}, \mathrm{GP}, \mathrm{NP}$ 각각 $19.30^{\circ} \mathrm{C}, 31.60^{\circ} \mathrm{C}, 23.00^{\circ} \mathrm{C}$ 이며, 습도 의 변화폭은 각각 $43.30 \%, 63.80 \%, 64.7 \%$ 이었다. 따라서 온습도 변화 폭은 $\mathrm{OP}$ 가 가장 적었으며, GP가 변화폭이 가장 큰 것으로 보였다. 또한 평균온도는 GP가 가장 높았으 며, 습도 가장 낮게 유지되었다.

\section{색 도}

곶감의 표면 색택은 외관상 품질을 판정할 수 있는 중요 한 요소로 판단되며, lightness를 나타내는 $\mathrm{L}^{*}$ 값의 변화는 저장 중 감의 갈변에서 시작된다고 판단된다(17). 곶감 갈변 은 주로 비효소적인 mailiard 반응에 의해 이루어지고, 일부 불활성화 되지 않은 갈변효소도 관여할 수 있을 것으로 여겨지며, 비효소적 갈변반응의 반응인자들에는 아미노산, 당 구성, 온도, $\mathrm{pH}$ 등이 있다고 알려져 있다(18). Table 1은 저장조건에 따른 농가별 건시의 외부 및 내부 색도 변화를 나타낸 표이다. 외부 변화를 살펴보았을 때, 외부 $\mathrm{L}^{*}$ 값은 백분의 생성으로 인해 모든 시료가 저장 중 증가하다가 감소하는 모습을 보이고 있고 $\mathrm{OGP}$ 는 실험마다 유의적 차 이를 내며 변화하였으며 초기값에 비하여 변화량이 큰 것을 볼 수 있었다. OGP의 $\mathrm{a}^{*}, \mathrm{~b}^{*}$ 값은 저장 90 일 차부터 크게 감소하는 모습을 볼 수 있었다. 반면 $\mathrm{ONP}$ 는 $\mathrm{L}^{*}, \mathrm{a}^{*}, \mathrm{~b}^{*}$ 모두 큰 변화가 없었다. 이 전의 보고에 따르면 관행적인 상자포 장을 했을 때 저장온도 $-20^{\circ} \mathrm{C}$ 에서 저장 한계 기간이 최대 6 개월이며, 품질저하의 원인은 백분의 변화 및 변색이라고 하였다(19). 시료로 사용된 건시는 이 보고보다 수분함량이 더 높으므로 90 일 차부터 외관 백분의 변화가 빨리 발생되 었을 것으로 보이며, 저장온도가 $-20^{\circ} \mathrm{C}$ 보다 약 $4{ }^{\circ} \mathrm{C}$ 가량 높 았던 OGP가 가장 많이 변화하였다. 건시의 내부 변화를 관찰해 보았을 때는 $\mathrm{L}^{*}$ 은 모든 시료가 저장 60 일 차까지 증가했으며, 60 일 차에 최대로 내부색도가 밝아진 것을 알 수 있다. 하지만 저장 60 일 차 이후로는 그 값이 유의적으로 감소하였다. $\mathrm{a}^{*}$ 값은 시료 IOP와 INP에서는 큰 변화를 보이 지 않았고, IGP는 저장 기간 동안 유의적으로 감소하였다. $\mathrm{Oh}(20)$ 의 보고에 따르면 곶감의 적색도는 덕장의 위치가 크게 영향을 미친다고 하였다. $\mathrm{b}^{*}$ 값의 변화는 시료 IOP와 $\mathrm{INP}$ 는 60 일 차를 제외하고 초기값과 유사하였으며, IGP는 초기값에 비해 유의적으로 감소하였다. 모든 시료가 저장 기간에 따라 일관적인 결과를 보이지 않고 작은 오차들이 나타나는 것들은 감의 적색도와 황색도는 원료감의 숙도에 따라 영향을 미칠 수 있다는 Jung 등(21)의 보고로 해석할 수 있다. 미숙과는 내부가 푸른색을 띠고, 적숙과는 과실 전체가 등황색, 완숙과는 진홍색을 띤다는 보고에 따라, 

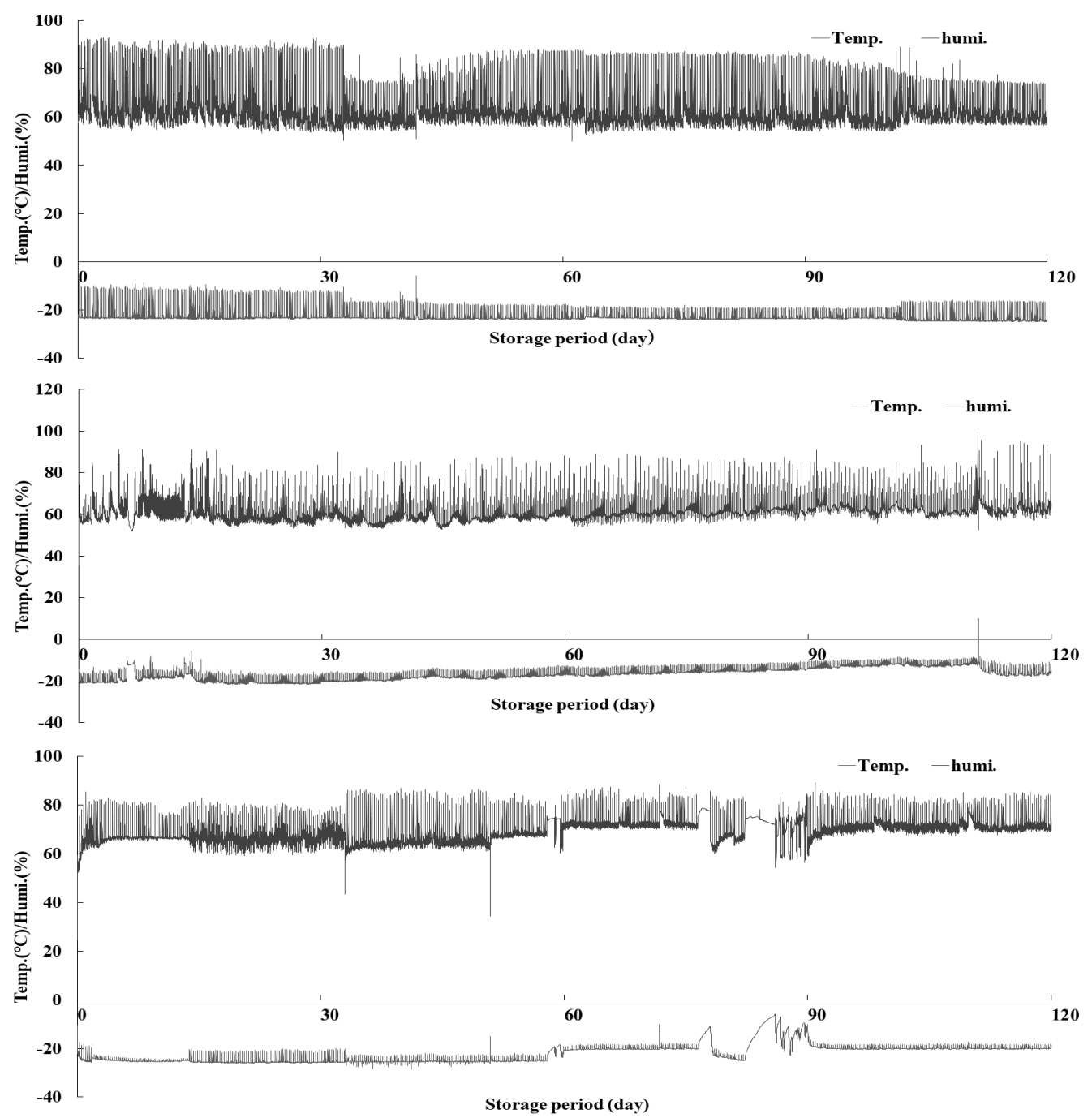

Fig. 1. Changes of temperature and humidity in different farmhouses during storage period. OP, Oenam-myeon persimmons; GP, Geodong-dong persimmons; NP, Naeseo-myeon persimmons.

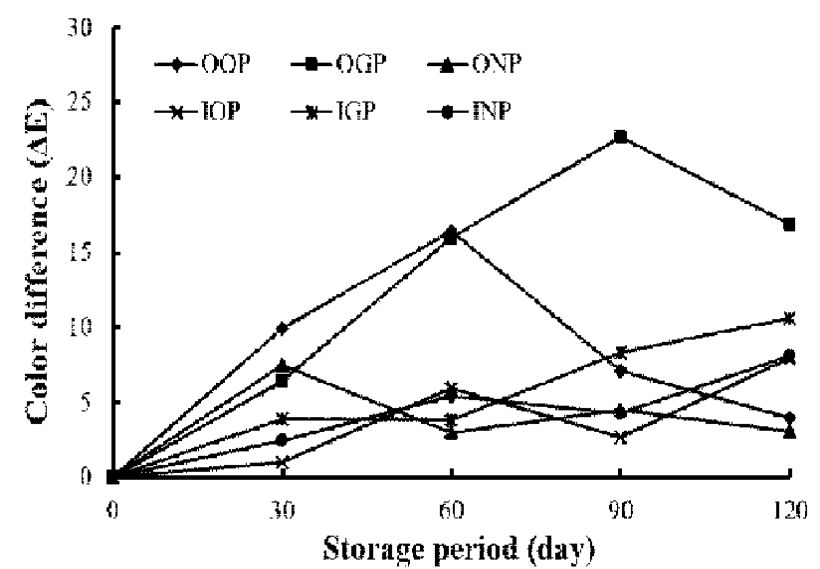

Fig. 2. Color difference $(\Delta \mathrm{E})$ of dried persimmons in different farmhouses during storage period.

OOP, OGP and ONP; Outside of OP (Oenam-myeon persimmons), GP (Geodong-dong persimmons) and NP (Naeseo-myeon persimmons), respectively. IOP, IGP and INP; Inside of OP, GP and NP, respectively.
$\mathrm{OP}, \mathrm{GP}, \mathrm{NP}$ 의 초기 색도의 차이는 원료감의 숙도에 따른 것으로 보인다(22). Fig. 2는 시료의 외부 색도와 내부 색도 의 초기값에 대한 색차값을 나타낸 그래프이다. 색차 산출 결과 색도 변화 정도는 OGP가 계속 증가하여 저장 90 일 차에 가장 크게 증가 했으며, 저장기간 전체에서 가장 큰 값을 보였다. 다음으로 $\mathrm{OOP}$ 의 색도가 저장 60 일 차에 크게 변하였으며, $\mathrm{ONP}$ 의 색도는 초기와 큰 변화를 보이지 않 았다.

$\mathrm{IOP}$ 와 INP는 유사한 양상과 값을 보였으며, IGP는 저장 기간 중 점차 색차값이 증가하는 모습을 볼 수 있다.

\section{이화학적 품질 특성 분석}

수분함량은 곶감의 조직감, 백분 생성, 외관 등을 변화시 킬 수 있는 중요한 요소로서 곶감의 품질 평가를 하는 것에 있어 꼭 필요한 항목이라고 할 수 있다. 저장 조건 및 환경에 
Table $1 . \mathrm{L}^{*}, \mathrm{a}^{*}$ and $\mathrm{b}^{*}$ values of dried persimmons (inside) in different farmhouses during storage period

\begin{tabular}{|c|c|c|c|c|c|c|}
\hline \multirow{2}{*}{\multicolumn{2}{|c|}{ Sample ${ }^{1)}$}} & \multicolumn{5}{|c|}{ Storage period (day) } \\
\hline & & 0 & 30 & 60 & 90 & 120 \\
\hline \multirow{3}{*}{$\mathrm{L}^{*}$} & OOP & $38.11 \pm 1.39^{2) \mathrm{a} 3)}$ & $45.71 \pm 4.76^{c}$ & $49.72 \pm 4.46^{\mathrm{d}}$ & $44.25 \pm 3.21^{\mathrm{bc}}$ & $41.46 \pm 4.60^{\mathrm{b}}$ \\
\hline & OGP & $36.61 \pm 2.06^{\mathrm{a}}$ & $41.18 \pm 3.40^{\mathrm{b}}$ & $52.52 \pm 3.43^{\mathrm{c}}$ & $55.67 \pm 4.41^{\mathrm{d}}$ & $50.70 \pm 5.47^{\circ}$ \\
\hline & ONP & $40.38 \pm 2.92^{\mathrm{a}}$ & $47.24 \pm 4.44^{\mathrm{c}}$ & $43.17 \pm 4.14^{\mathrm{ab}}$ & $44.83 \pm 5.85^{\mathrm{bc}}$ & $40.01 \pm 5.22^{\mathrm{a}}$ \\
\hline \multirow{3}{*}{$a^{*}$} & $\mathrm{OOP}$ & $6.85 \pm 0.84^{\mathrm{a}}$ & $9.89 \pm 2.83^{\text {cd }}$ & $10.93 \pm 1.62^{d}$ & $7.98 \pm 1.78^{\mathrm{ab}}$ & $8.73 \pm 2.23^{\mathrm{bc}}$ \\
\hline & OGP & $9.13 \pm 1.09^{c}$ & $8.06 \pm 1.53^{\mathrm{c}}$ & $8.55 \pm 2.14^{\mathrm{c}}$ & $3.73 \pm 0.73^{\mathrm{a}}$ & $6.66 \pm 2.51^{b}$ \\
\hline & ONP & $7.21 \pm 1.29^{\mathrm{ab}}$ & $5.38 \pm 1.13^{\mathrm{a}}$ & $8.01 \pm 2.60^{b}$ & $7.79 \pm 1.95^{\mathrm{b}}$ & $10.08 \pm 4.47^{\circ}$ \\
\hline \multirow{3}{*}{$b^{*}$} & $\mathrm{OOP}$ & $19.12 \pm 1.85^{\mathrm{ab}}$ & $24.75 \pm 5.65^{c}$ & $30.03 \pm 6.61^{\mathrm{d}}$ & $22.57 \pm 5.62^{\mathrm{bc}}$ & $18.05 \pm 5.57^{\mathrm{a}}$ \\
\hline & OGP & $22.41 \pm 3.20^{\mathrm{c}}$ & $18.06 \pm 2.49^{\mathrm{b}}$ & $24.18 \pm 5.32^{c}$ & $11.34 \pm 1.60^{\mathrm{a}}$ & $13.42 \pm 2.98^{\mathrm{a}}$ \\
\hline & ONP & $17.05 \pm 3.40^{\mathrm{ab}}$ & $14.68 \pm 2.54^{\mathrm{a}}$ & $17.83 \pm 3.56^{b}$ & $16.71 \pm 2.53^{\mathrm{ab}}$ & $17.99 \pm 4.26^{b}$ \\
\hline \multirow{3}{*}{$L^{*}$} & IOP & $36.20 \pm 2.76^{b}$ & $35.54 \pm 1.22^{\mathrm{b}}$ & $39.68 \pm 1.49^{\mathrm{a}}$ & $33.64 \pm 2.43^{b}$ & $28.67 \pm 7.21^{\mathrm{a}}$ \\
\hline & IGP & $40.21 \pm 2.41^{\mathrm{c}}$ & $41.95 \pm 2.73^{\mathrm{cd}}$ & $43.29 \pm 3.01^{\mathrm{d}}$ & $37.18 \pm 2.68^{b}$ & $33.26 \pm 2.63^{\mathrm{a}}$ \\
\hline & INP & $42.09 \pm 2.38^{\mathrm{c}}$ & $44.46 \pm 2.90^{\mathrm{d}}$ & $46.72 \pm 2.12^{\mathrm{e}}$ & $40.34 \pm 2.39^{b}$ & $34.08 \pm 1.32^{\mathrm{a}}$ \\
\hline \multirow{3}{*}{$a^{*}$} & IOP & $6.02 \pm 2.18^{\mathrm{a}}$ & $5.33 \pm 1.76^{\mathrm{a}}$ & $9.02 \pm 2.97^{b}$ & $5.16 \pm 1.32^{\mathrm{a}}$ & $7.00 \pm 2.92^{\mathrm{a}}$ \\
\hline & IGP & $9.26 \pm 1.67^{\mathrm{c}}$ & $7.59 \pm 2.47^{b}$ & $8.06 \pm 2.08^{b c}$ & $5.29 \pm 1.36^{\mathrm{a}}$ & $4.42 \pm 1.53^{\mathrm{a}}$ \\
\hline & INP & $11.53 \pm 2.01^{\mathrm{bc}}$ & $10.12 \pm 2.52^{\mathrm{b}}$ & $11.51 \pm 1.68^{\mathrm{bc}}$ & $8.18 \pm 2.20^{\mathrm{a}}$ & $12.30 \pm 2.61^{\circ}$ \\
\hline \multirow{3}{*}{$b^{*}$} & IOP & $8.44 \pm 3.22^{\mathrm{a}}$ & $8.86 \pm 2.60^{\mathrm{a}}$ & $12.23 \pm 3.46^{b}$ & $8.54 \pm 2.00^{\mathrm{a}}$ & $10.72 \pm 3.28^{\mathrm{at}}$ \\
\hline & IGP & $12.99 \pm 2.35^{\mathrm{b}}$ & $10.79 \pm 4.20^{b}$ & $11.09 \pm 2.89^{\mathrm{ab}}$ & $6.35 \pm 1.84^{\mathrm{a}}$ & $6.64 \pm 1.4^{\mathrm{a}}$ \\
\hline & INP & $14.93 \pm 2.98^{\mathrm{a}}$ & $14.01 \pm 4.10^{\mathrm{a}}$ & $17.76 \pm 2.76^{b}$ & $12.95 \pm 3.39^{\mathrm{a}}$ & $14.65 \pm 2.10^{\mathrm{a}}$ \\
\hline
\end{tabular}

${ }^{1)}$ OOP, OGP and ONP; Outside of OP (Oenam-myeon persimmons), GP (Geodong-dong persimmons) and NP (Naeseo-myeon persimmons), respectively. IOP, IGP and INP; Inside of OP, GP and NP, respectively.

${ }^{2)}$ Means \pm SD.

${ }^{3) a-c}$ Means in a row followed by different superscripts are significantly different $(\mathrm{p}<0.05)$ by Duncan's multiple range test.

Table 2. Physicochemical property of dried persimmons in different farmhouses during storage period

\begin{tabular}{|c|c|c|c|c|c|c|}
\hline \multirow{2}{*}{\multicolumn{2}{|c|}{ Sample ${ }^{1)}$}} & \multicolumn{5}{|c|}{ Storage period (day) } \\
\hline & & 0 & 30 & 60 & 90 & 120 \\
\hline \multirow{3}{*}{$\begin{array}{l}\text { Moisture } \\
\text { contents } \\
(\%)\end{array}$} & $\mathrm{OP}$ & $42.89 \pm 0.30^{22 b 3)}$ & $40.63 \pm 1.88^{\mathrm{a}}$ & $43.50 \pm 0.66^{b}$ & $43.60 \pm 0.50^{b}$ & $48.67 \pm 0.92^{c}$ \\
\hline & GP & $40.01 \pm 0.31^{b}$ & $40.49 \pm 0.18^{c}$ & $39.86 \pm 0.20^{\mathrm{ab}}$ & $41.67 \pm 0.16^{d}$ & $39.53 \pm 0.20^{\mathrm{a}}$ \\
\hline & $\mathrm{NP}$ & $39.61 \pm 0.30^{\mathrm{a}}$ & $41.29 \pm 0.43^{b}$ & $41.29 \pm 0.57^{b}$ & $41.97 \pm 1.16^{b}$ & $41.54 \pm 0.28^{\mathrm{b}}$ \\
\hline \multirow{3}{*}{$\begin{array}{l}\text { Glucose } \\
(\mathrm{mg} / \mathrm{mL})\end{array}$} & $\mathrm{OP}$ & $18.85 \pm 3.73^{\mathrm{a}}$ & $20.27 \pm 0.71^{a}$ & $22.35 \pm 0.89^{\mathrm{ab}}$ & $25.24 \pm 2.14^{b}$ & $26.14 \pm 0.76^{b}$ \\
\hline & GP & $19.96 \pm 1.53^{\mathrm{a}}$ & $21.36 \pm 3.05^{\mathrm{a}}$ & $26.86 \pm 2.25^{b}$ & $27.60 \pm 0.40^{b}$ & $29.25 \pm 0.14^{b}$ \\
\hline & NP & $24.59 \pm 0.96^{b}$ & $23.73 \pm 1.67^{b}$ & $21.58 \pm 1.58^{\mathrm{a}}$ & $23.25 \pm 0.15^{\mathrm{ab}}$ & $25.40 \pm 0.29^{b}$ \\
\hline \multirow{3}{*}{$\begin{array}{l}\text { Fructose } \\
(\mathrm{mg} / \mathrm{mL})\end{array}$} & $\mathrm{OP}$ & $17.91 \pm 2.20^{\mathrm{a}}$ & $20.90 \pm 3.31^{a}$ & $27.59 \pm 1.42^{b}$ & $27.80 \pm 0.50^{b}$ & $26.84 \pm 0.77^{b}$ \\
\hline & GP & $19.06 \pm 1.30^{\mathrm{a}}$ & $20.26 \pm 3.00^{\mathrm{a}}$ & $29.83 \pm 1.97^{\mathrm{b}}$ & $28.36 \pm 0.06^{b}$ & $27.41 \pm 0.28^{b}$ \\
\hline & $\mathrm{NP}$ & $23.24 \pm 0.72^{\mathrm{a}}$ & $30.40 \pm 2.02^{\mathrm{b}}$ & $24.23 \pm 1.87^{\mathrm{a}}$ & $29.70 \pm 0.10^{b}$ & $31.66 \pm 0.36^{b}$ \\
\hline
\end{tabular}

${ }^{1)} \mathrm{OP}$, Oenam-myeon persimmons; GP, Geodong-dong persimmons; NP, Naeseo-myeon persimmons.

${ }^{2)}$ Means \pm SD.

${ }^{37)-c}$ Means in a row followed by different superscripts are significantly different $(\mathrm{p}<0.05)$ by Duncan's multiple range test.

따른 건시의 수분 함량변화는 Table 2에 나타내었다. 수분 함량은 저장기간 동안 39.53-48.67\% 범위로 나타났으며 $\mathrm{Kim}$ 등(23)의 연구에서 상주곶감의 평균 수분함량이 $38.20 \%$ 였다는 결과에 비해 더 높은 값이었다. 이는 최근
소비자들이 촉촉한 식감을 가진 반건시를 선호하고 수율도 증대시키기 위해서 과거에 비해 건조를 적게 한 건시를 유통하는 것으로 보인다. $\mathrm{OP}$ 의 수분함량은 저장 30 일 차에 감소하였다가 60 일 차 이후 유의적으로 증가하는 모습을 
Table 3. Texture of dried persimmons in different farmhouses during storage period

\begin{tabular}{|c|c|c|c|c|c|c|}
\hline \multirow{2}{*}{ Sample ${ }^{1}$} & & \multicolumn{5}{|c|}{ Storage period (day) } \\
\hline & & 0 & 30 & 60 & 90 & 120 \\
\hline \multirow{3}{*}{$\begin{array}{c}\text { Hardness } \\
\left(\mathrm{g} / \mathrm{cm}^{2}\right)\end{array}$} & OP & $263.08 \pm 20.70^{2 \mathrm{ab} 33}$ & $362.09 \pm 65.41^{\mathrm{c}}$ & $294.83 \pm 39.14^{b}$ & $252.15 \pm 84.45^{\mathrm{ab}}$ & $227.06 \pm 90.66^{\mathrm{a}}$ \\
\hline & GP & $269.39 \pm 81.30^{\mathrm{a}}$ & $448.88 \pm 122.47^{a}$ & $1,097.68 \pm 119.71^{\mathrm{c}}$ & $870.24 \pm 313.14^{b}$ & $1,247.03 \pm 339.36^{\circ}$ \\
\hline & $\mathrm{NP}$ & $462.48 \pm 64.23^{\mathrm{a}}$ & $676.57 \pm 111.39^{b}$ & $576.18 \pm 230.10^{\mathrm{ab}}$ & $460.30 \pm 91.93^{\mathrm{a}}$ & $469.23 \pm 129.89^{\mathrm{a}}$ \\
\hline \multirow{3}{*}{$\begin{array}{c}\text { Chewiness } \\
\text { (g) }\end{array}$} & OP & $438.69 \pm 61.45^{\mathrm{a}}$ & $956.67 \pm 190.62^{b}$ & $1,261.59 \pm 148.35^{\mathrm{c}}$ & $652.20 \pm 242.21^{\mathrm{a}}$ & $715.87 \pm 588.15^{\mathrm{ab}}$ \\
\hline & GP & $1,010.60 \pm 186.67^{\mathrm{a}}$ & $888.10 \pm 267.30^{\mathrm{a}}$ & $2,386.23 \pm 214.69^{c}$ & $1,141.35 \pm 248.04^{\mathrm{a}}$ & $2,061.14 \pm 652.46^{b}$ \\
\hline & $\mathrm{NP}$ & $1,237.00 \pm 360.35^{\mathrm{ab}}$ & $1,379.72 \pm 147.07^{b}$ & $1,681.30 \pm 194.18^{c}$ & $1,086.12 \pm 115.11^{\mathrm{ab}}$ & $1,013.88 \pm 555.88^{\mathrm{a}}$ \\
\hline \multirow{3}{*}{$\begin{array}{c}\text { Springiness } \\
(\%)\end{array}$} & OP & $103.65 \pm 1.50^{c}$ & $101.36 \pm 2.03^{\mathrm{b}}$ & $102.79 \pm 1.80^{\mathrm{bc}}$ & $98.69 \pm 3.34^{\mathrm{a}}$ & $103.61 \pm 0.86^{c}$ \\
\hline & GP & $103.20 \pm 1.00^{\mathrm{b}}$ & $102.04 \pm 1.18^{\mathrm{ab}}$ & $101.65 \pm 0.93^{\mathrm{ab}}$ & $99.22 \pm 7.55^{b}$ & $100.76 \pm 0.33^{\mathrm{ab}}$ \\
\hline & $\mathrm{NP}$ & $102.56 \pm 1.30^{c}$ & $101.54 \pm 0.52^{b}$ & $101.65 \pm 0.55^{b}$ & $100.11 \pm 0.60^{\mathrm{a}}$ & $101.07 \pm 0.29^{b}$ \\
\hline \multirow{3}{*}{$\begin{array}{l}\text { Cohesiveness } \\
(\%)\end{array}$} & $\mathrm{OP}$ & $127.41 \pm 14.01^{\mathrm{a}}$ & $272.42 \pm 96.38^{\mathrm{c}}$ & $245.02 \pm 75.57^{\mathrm{bc}}$ & $212.15 \pm 61.30^{\mathrm{bc}}$ & $202.08 \pm 69.46^{b}$ \\
\hline & GP & $254.51 \pm 53.19^{\mathrm{c}}$ & $199.40 \pm 92.25^{\mathrm{b}}$ & $180.79 \pm 37.66^{\mathrm{bc}}$ & $176.59 \pm 68.27^{\mathrm{bc}}$ & $136.37 \pm 21.87^{\mathrm{a}}$ \\
\hline & $\mathrm{NP}$ & $187.37 \pm 42.58^{\mathrm{ab}}$ & $186.61 \pm 58.77^{\mathrm{ab}}$ & $181.02 \pm 51.31^{\mathrm{ab}}$ & $201.13 \pm 46.22^{\mathrm{b}}$ & $147.55 \pm 28.30^{\mathrm{a}}$ \\
\hline
\end{tabular}

${ }^{1)} \mathrm{OP}$, Oenam-myeon persimmons; GP, Geodong-dong persimmons; NP, Naeseo-myeon persimmons.

${ }^{2)}$ Means \pm SD.

${ }^{37)-c}$ Means in a row followed by different superscripts are significantly different $(\mathrm{p}<0.05)$ by Duncan's multiple range test

Table 4. Sensory evaluation of dried persimmons in different farmhouses during storage period

(Score)

\begin{tabular}{ccccccc}
\hline \multirow{2}{*}{ Sample $^{\mathrm{l})}$} & & \multicolumn{5}{c}{ Storage period (day) } \\
\cline { 3 - 7 } Color & & 0 & 30 & 60 & 90 & 120 \\
& OP & $4.33 \pm 1.34^{2) \mathrm{a} 3)}$ & $4.20 \pm 1.14^{\mathrm{a}}$ & $4.33 \pm 0.89^{\mathrm{a}}$ & $4.33 \pm 1.44^{\mathrm{a}}$ & $5.06 \pm 0.88^{\mathrm{a}}$ \\
& GP & $4.66 \pm 1.04^{\mathrm{b}}$ & $5.60 \pm 0.82^{\mathrm{c}}$ & $5.06 \pm 1.16^{\mathrm{bc}}$ & $3.73 \pm 1.16^{\mathrm{a}}$ & $3.6 \pm 1.35^{\mathrm{a}}$ \\
& NP & $5.86 \pm 1.24^{\mathrm{a}}$ & $6.00 \pm 1.19^{\mathrm{ab}}$ & $6.66 \pm 0.61^{\mathrm{b}}$ & $6.33 \pm 0.61^{\mathrm{ab}}$ & $6.33 \pm 0.97^{\mathrm{ab}}$ \\
\hline \multirow{5}{*}{ Texture } & OP & $4.80 \pm 0.94^{\mathrm{a}}$ & $4.53 \pm 1.72^{\mathrm{a}}$ & $4.66 \pm 1.29^{\mathrm{a}}$ & $4.86 \pm 1.50^{\mathrm{a}}$ & $5.20 \pm 1.26^{\mathrm{a}}$ \\
& GP & $5.06 \pm 1.16^{\mathrm{a}}$ & $5.20 \pm 0.67^{\mathrm{a}}$ & $5.20 \pm 1.42^{\mathrm{a}}$ & $5.06 \pm 1.09^{\mathrm{a}}$ & $4.40 \pm 1.45^{\mathrm{a}}$ \\
& NP & $5.53 \pm 1.30^{\mathrm{a}}$ & $5.73 \pm 0.88^{\mathrm{a}}$ & $5.60 \pm 1.12^{\mathrm{a}}$ & $5.06 \pm 1.09^{\mathrm{a}}$ & $5.06 \pm 1.48^{\mathrm{a}}$ \\
\hline \multirow{5}{*}{ Sweetness } & OP & $5.13 \pm 1.30^{\mathrm{a}}$ & $5.00 \pm 1.85^{\mathrm{a}}$ & $4.93 \pm 1.57^{\mathrm{a}}$ & $5.00 \pm 1.13^{\mathrm{a}}$ & $5.73 \pm 0.70^{\mathrm{a}}$ \\
& GP & $5.20 \pm 1.26^{\mathrm{ab}}$ & $5.53 \pm 1.12^{\mathrm{b}}$ & $5.40 \pm 1.05^{\mathrm{ab}}$ & $5.00 \pm 1.51^{\mathrm{ab}}$ & $4.46 \pm 1.24^{\mathrm{a}}$ \\
& NP & $5.40 \pm 1.24^{\mathrm{a}}$ & $5.53 \pm 1.35^{\mathrm{a}}$ & $5.06 \pm 1.27^{\mathrm{a}}$ & $5.06 \pm 1.09^{\mathrm{a}}$ & $5.20 \pm 1.14^{\mathrm{a}}$ \\
\hline \multirow{5}{*}{ Appearance } & OP & $4.80 \pm 1.20^{\mathrm{a}}$ & $3.93 \pm 1.53^{\mathrm{a}}$ & $4.26 \pm 1.03^{\mathrm{a}}$ & $4.80 \pm 1.32^{\mathrm{a}}$ & $5.80 \pm 0.77^{\mathrm{b}}$ \\
& GP & $4.73 \pm 0.88^{\mathrm{ab}}$ & $5.46 \pm 1.06^{\mathrm{b}}$ & $5.53 \pm 1.18^{\mathrm{b}}$ & $4.20 \pm 1.37^{\mathrm{ac}}$ & $3.73 \pm 1.48^{\mathrm{c}}$ \\
& NP & $5.80 \pm 1.14^{\mathrm{ab}}$ & $6.60 \pm 0.82^{\mathrm{b}}$ & $6.26 \pm 0.88^{\mathrm{ab}}$ & $5.60 \pm 1.29^{\mathrm{a}}$ & $5.66 \pm 1.04^{\mathrm{a}}$ \\
\hline \multirow{2}{*}{ Overall } & OP & $4.53 \pm 0.83^{\mathrm{a}}$ & $4.33 \pm 1.63^{\mathrm{a}}$ & $4.80 \pm 1.01^{\mathrm{a}}$ & $5.00 \pm 1.41^{\mathrm{a}}$ & $5.93 \pm 0.70^{\mathrm{b}}$ \\
& GP & $5.40 \pm 1.12^{\mathrm{bc}}$ & $5.80 \pm 1.20^{\mathrm{c}}$ & $5.60 \pm 0.98^{\mathrm{bc}}$ & $4.86 \pm 0.99^{\mathrm{ab}}$ & $4.13 \pm 0.91^{\mathrm{a}}$ \\
& NP & $5.53 \pm 1.18^{\mathrm{a}}$ & $5.86 \pm 0.74^{\mathrm{a}}$ & $6.00 \pm 1.06^{\mathrm{a}}$ & $5.86 \pm 0.74^{\mathrm{a}}$ & $5.46 \pm 0.91^{\mathrm{a}}$ \\
\hline
\end{tabular}

${ }^{1)} \mathrm{OP}$, Oenam-myeon persimmons; GP, Geodong-dong persimmons; NP, Naeseo-myeon persimmons.

${ }^{2}$ Means \pm SD.

${ }^{37)-c}$ Means in a row followed by different superscripts are significantly different $(\mathrm{p}<0.05)$ by Duncan's multiple range test.

볼 수 있고, GP 수분함량의 증가와 감소가 반복되었다. NP 는 30 일 차 이후 변화가 없는 것으로 보였다.

유리당 함량 분석 결과는 Table 2에 나타내었다. 시료 모두 공통적으로 glucose와 fructose만이 다량 검출되었고
기타 sucrose와 manitol 등은 극히 미량 검출되었는데 이는 Im 등(16)의 곶감의 유리당 분석 결과 glucose와 fructose만 이 검출되었다는 보고와 일치하였다. 또한 연화기간이 경 과하면서 포도당과 과당은 증가하고 자당은 감소하여 품종 
에 따라 sucrose가 검출되지 않는다는 보고가 있었다(24).

Glucose 함량은 OP와 GP가 증가하는 모습을 보였고, 특 히 $\mathrm{GP}$ 의 값이 초기 값에 비해 $46.54 \%$ 증가하여 시료 중 가장 크게 증가했다. NP의 glucose 함량이 초기 값과 변화가 가장 적으며, 모든 구에서 저장 60 일 차 이후로는 큰 변화가 나타나지 않았다. Fructose도 저장 중 증가하는 모습을 보였 다. $\mathrm{OP}$ 와 $\mathrm{GP}$ 는 저장 60 일 차까지는 증가하다가 이후로는 큰 변화가 나타나지 않았다. NP는 30 일 차를 제외하고는 꾸준히 증가하였다.

\section{조직감}

조직감 분석 결과는 Table 3에 나타내었다. Hardness 항 목에서 $\mathrm{OP}$ 와 $\mathrm{NP}$ 는 모두 증가하다 감소하는 경향을 보였지 만 큰 변화는 없었으며, $\mathrm{GP}$ 는 저장 기간 동안 유의적인 차이를 보이며 크게 경화되는 모습을 볼 수 있다. 이는 Table 2 에서 나타난 수분 함량 감소에 의한 것으로 설명할 수 있다. Chewiness는 $\mathrm{OP}, \mathrm{GP}, \mathrm{NP}$ 모두 저장 60 일 차에 각각 $1,261.59,2,386.23,1,681.30$ 으로 최대로 증가하였으나 다시 감소하는 모습을 보였다. NP는 큰 변화를 보이지 않았으나 $\mathrm{OP}$ 와 $\mathrm{GP}$ 의 chewiness는 저장 중 초기 값의 두배 이상으로 증가하는 모습을 보였다. 저장 환경에 따른 조건은 건시의 springiness에 영향을 주지 못했다. 식품에 있어서 응집성은 식품고유의 형태를 유지하는데 필요한 내부 결합력, 즉 변 형에 대한 복원력을 나타내는 값이다(25). OP는 cohesiveness 가 초기 값보다 증가하였으며, GP는 크게 감소하여 내부 결합력 및 복원력이 떨어졌다. 또한 $\mathrm{NP}$ 는 저장 중 유의적 변화는 보이지 않았다.

\section{관능검사}

Table 4는 15 명의 훈련된 패널들에 의한 관능검사 점수를 표로 나타낸 것이다. Color 항목에서 $\mathrm{OP}$ 와 $\mathrm{NP}$ 는 점수가 증가하거나 유지되었으나, $\mathrm{GP}$ 는 저장 90 일 차부터 상품 가치 기준인 4점 이하로 점수가 떨어졌다. Texture와 sweetness 항목은 관능적으로 모든 구에서 기호적인 차이가 보이지 않았다. Appearance 항목은 GP가 저장 기간 동안 점차 감소함을 보였으며, 나머지 구들은 증가하거나 유지 되었다. 전반적 기호도 점수는 $\mathrm{OP}$ 는 증가하는 모습을 보였 고, $\mathrm{NP}$ 는 초기와 변화가 없었으며, GP는 감소하는 모습을 보였다.

\section{요 약}

본 연구는 저장 조건을 달리 한 농가 3곳의 건시를 저장하 면서 품질 특성변화를 비교 및 분석하였다. 건시는 각각 $\mathrm{OP}, \mathrm{GP}, \mathrm{NP}$ 로 지칭하였으며 저장된 건시는 30 일 간격으로 각 농가의 시료를 취하여 품질 변화를 실험, 분석하였다.
색도의 경우 내부 온습도 변화와 평균 온도가 가장 크고 습도가 가장 낮게 유지된 GP가 가장 유의미한 변화량을 보였다. OOP, IOP, ONP, INP의 변화값에 비해 OGP, IGP는 초기값에서 유의적으로 감소하였다. 색차의 산출결과 색도 변화에서도 OGP는 저장 기간 전체에서 가장 큰 값을 보였 으며 IGP의 경우에도 큰 변화가 없는 IOP와 INP에 비해 저장기간 중 점차 색차값이 증가하였다. Glucose함량은 OP 와 GP가 함께 증가하는 경향을 보였으며, 그 중 GP가 초기 값에 비해 가장 크게 증가하였다. Fructose함량의 경우도 $\mathrm{OP}$ 와 GP가 둘 다 증가하는 경향을 보였으며, 저장 60 일 차 이후에는 큰 변화가 없었다. 조직감의 경우에도 큰 변화 가 없는 $\mathrm{OP}$ 와 $\mathrm{NP}$ 와는 다르게 $\mathrm{GP}$ 는 유의적인 차이를 보이 며 크게 경화하는 경향을 보였다. 관능 검사의 경우 전반적 기호도, 특히 color항목에서 $\mathrm{GP}$ 는 지속적으로 감소하는 모 습을 보였다. 이상의 결과를 종합하였을 때, 소비자들의 건시에 대한 위생성, 안정성을 보장하고 품질을 향상시켜 기호성을 증대하기 위해서 내부 온습도 변화를 최대한 감소 시켜야 하며, 이를 위해 일관성 있는 저장조건을 유지함의 중요함을 알 수 있었다. 향후 실제 농가에서 적합한 건시의 저장 및 유통조건 설정에 도움이 될 것이라고 사료된다.

\section{References}

1. Kim JK, Kang WW, Oh SL, Kim JH, Han JH, Moon HK, Choi JU (2004) Comparison of quality characteristics on traditional dried persimmons from various regions. J Korean Soc Food Sci Nutr, 33, 140-145

2. Kim KH, Kim KM (2014) Food quality comparison of dried persimmons (Diospyros kaki THUNB) when using medicinal plant extracts and food additives during drying process. Curr Res Agric Life Sci, 32, 10-17

3. Seo JH, Jeong YJ, Kim KS (2000) Physiological characteristics of tannins isolated from astringent persimmon fruits. Korean J Food Sci Technol, 32, 212-217

4. Kim YB, Lee JS, Lim BS (1995) Survey on utilization of processing and storage the astringent persimmons. Research report of Expansion plan in regard to use the persimmons, gardening research institute, Suwon, Korea, p 15-31

5. Kim JK, Kim YB, Jang HS (1993) Improved persimmon drying method. Horticultural Experiment Station Research Report, Suwon, Korea, p 344-349

6. Kim JK, Jang HS, Jung ST, Kim YB (1996) Effect of gas-exchange packaging on quality of dried Persimmons during storage, RDA J Agri Sci, 38, 909-914 
7. Kim HY, Chnag HJ (1995) Changes of physicochemical properties during the preparation of persimmon pickles and its optimal preparation conditions. Korean J Food Sci Technol, 27, 697-702

8. Park HW, Cha HS, Kim SH, Park HR, Lee SA, Kim YH (2006) Effects of grapefruit seed extract pretreatment and packaging material on quality of dried persimmons. Korean J Food Preserv, 13, 168-173

9. Park HW, Lee SA, Cha HS, Kim YH (2005) Effect of cinnamon pretreatment and packaging materials on the quality of dried persimmon. Korean J Food Preserv, 12, 305-309

10. Kim SH, Park HW, Lee SA, Kim YH, Cha HS (2004) Quality changes of dried persimmons depending on pre-treatment and packaging materials during storage. Korean J Food Preserv, 11, 437-440

11. Park HW, Kim SH, Lee SA, Park JD (2012) Quality change of chill-stored dried persimmons affected by cinnamon extract pre-treatment and packaging condition. Korean J Packag Sci Technol, 18, 9-14

12. Lee YH (2013) Cultivation of Persimmons-Agricultural Technology Assistant. Rural Development Administration, Jeonju, Korea, p 16

13. Kim CI (2017) Forestry observation result (astringent persimmons). Korea Rural Economic Institute, 396, 2-3

14. National Forestry Cooperative Federation (2014) astringent persimmons business development plan, Korea Forest Service, Seoul, Korea, p 4

15. KREI (2015) Forest Products Production Survey. KREI 11-1400000-000529-13

16. AOAC (2000) Official Methods of Analysis. $17^{\text {th }}$ ed, Association of official analytical chemists, Washington DC, USA
17. Im JS, Lee MH (2007) Physicochemical compositions of raw and dried Wolha persimmons. Korean J Food Preserv, 14, 611-616

18. Lee SA, Park HW, Kim SH, Kim YH (2007) Quality changes of dried persimmons th toe storage temperature and packaging materials. Korean J Packag Sci Tech, 13, 1-4

19. Lee YH, (2013) Cultivation of persimmons-agricultural technology assistant. Rural Development Administration, Jeonju, Korea, p 228

20. Oh SR (2002) Development of quality improvement of dried persimmon. Sepecial Lecture Abstract on the $20^{\text {th }}$ Conference, Korea Food Research Institute, Sangju, Korea, p 41-47

21. Jung KM, Song IK, Cho DH, Chou YD (2004) Quality preperties of semi-dried persimmons with various drying methods and ripeness degree. Korean J Food Preserv, 11, 189-194

22. Lee YH (2013) Cultivation of persimmons-agricultural technology assistant. Rural Development Administration, Jeonju, Korea, p 223

23. Kim JK, Kang WW, Oh SL, Kim JH, Han JH, Moon HK, Choi JU (2004) Comparison of quality characteristics on traditional dried persimmons from various regions. J Korean Soc Food Sci Nutr, 33, 140-145

24. Lee U, Jo DH, Lee MH, Song IK, Huang SI, Lee SH, Choi KS, Heo MS, Kim SY, Jeong KM (2009) Cultivation technique to improve fruit tree productionWalnut \& Astringent persimmon. Korea Forest Research Institute Research Book 31, Daejeon, Korea, p 218

25. Korean Food Science Society (2004) Dictionary of food science and technology. Gwang-il Munhwasa, Seoul, Korea, p 124 